$1-2018$

\title{
Asexual Reproduction of Marine Invertebrate Embryos and Larvae
}

Jonathan D. Allen

College of William and Mary, jdallen@wm.edu

Adam M. Reitzel

William Jaeckel

Follow this and additional works at: https://scholarworks.wm.edu/asbookchapters

Part of the Marine Biology Commons

\section{Recommended Citation}

Allen, J. D., Reitzel, A. M., and Jaeckle, W., Asexual reproduction of marine invertebrate embryos and larvae. In. Evolutionary Ecology of Marine Invertebrate Larvae. (2018). Edited by Tyler J. Carrier, Adam M. Reitzel, and Andreas Heyland: Oxford University Press.

This Book Chapter is brought to you for free and open access by the Arts and Sciences at W\&M ScholarWorks. It has been accepted for inclusion in Arts \& Sciences Book Chapters by an authorized administrator of W\&M ScholarWorks. For more information, please contact scholarworks@wm.edu. 


\title{
CHAPTER 5
}

\section{Asexual Reproduction of Marine Invertebrate Embryos and Larvae}

\author{
Jonathan D. Allen, Adam M. Reitzel, and William Jaeckle
}

\subsection{Introduction}

The life histories of marine invertebrates are incredibly diverse and provide a wealth of opportunities to develop and test hypotheses about how and why modes of reproduction, development, and behavior evolve within and among lineages. With respect to the evolution of reproductive and developmental mode, phylogenetic, adaptive, and functional hypotheses presented over the past century have predominantly focused on the evolution of reproductive traits (e.g., free spawning, brooding, encapsulation; Rouse and Fitzhugh, 1994), nutritional mode of larvae (e.g., planktotrophy and lecithotrophy; Strathmann, 1985; Hart et al., 1997), and developmental form (e.g., larval morphology; Jeffery and Swalla, 1992; direct and indirect development; Wray, 1995; McEdward and Janies, 1997). Frequently, but not exclusively, these hypotheses have been tied to changes in per-offspring investment (Emlet et al., 1987; Sinervo and McEdward, 1988; Emlet and Hoegh-Guldberg, 1997), and influential models of per-offspring investment often serve as a framework for studies of the evolution of developmental modes (Vance, 1973; Christiansen and Fenchel, 1979; Levitan, 2000). Phylogenetic assessment of the evolution of character states within lineages has revealed frequent shifts among life histories traits (McHugh and Rouse, 1998, and references therein).

In addition to these macroevolutionary changes among species, the life history exhibited by individuals may change in response to one or more environmental features (life history plasticity). Plasticity in the evolution of life histories has also been addressed with respect to such aspects of sexual reproduction as facultative progenesis, where larval stages develop gametes (Poulin, 2001), and poecilogony, where one individual or species exhibits different reproductive modes (Krug, 1998). One area of life history plasticity that is far more common, but has received less attention, is asexual reproduction.

Asexual reproduction during development occurs in most marine phyla (reviewed by Alvarado, 2000; Blackstone and Jasker, 2003) and may occur at multiple stages during the indirect development of some species. Despite, or perhaps because of, its broad distribution among phyla, diverse explanations for the adaptive value or evolutionary significance of asexual reproduction as a life history strategy have been offered. Adaptive explanations include the following: as a method to weather harsh environments (e.g., gemmules in sponges, statoblasts in bryozoans); as a short-term solution for escaping mutation load (Hurst and Peck, 1996); as a means to colonize and/or adapt to changing or new habitats (Maynard Smith, 1971); or as a means to persist at low population sizes (Gerber and Kokko, 2016). Several authors have addressed adult asexual propagation and regeneration across the animal kingdom (e.g., Ferretti and Geraudie 2001), but asexual propagation is also employed by pre-adult stages. In this chapter we aim to synthesize the literature describing asexual reproduction by embryonic and larval stages of marine invertebrates, with a particular focus on echinoderms, where the ecological and evolutionary costs and benefits of diverse modes of clonal replication have been most studied. We conclude with a list of open 
questions that may provide fruitful future research avenues to better understand this understudied life history trait of marine invertebrates.

\subsection{Types of Asexual Reproduction of and by Embryos and Larvae}

The general life history of a marine invertebrate has two potential stages where asexual propagation could occur after fertilization, but prior to the development of the adult stage: the developing embryo and, when present, the larva. Asexual reproduction in various marine invertebrates, as well as throughout all animal phyla, also occurs by an elimination of meiosis during reproduction (e.g., parthenogenesis, apomixis, automixis; Judson and Normark, 1996) and during the juvenile/adult stage (Blackstone and Jasker, 2003).

\subsubsection{Embryo}

Asexual propagation at the embryo stage is referred to as polyembryony. Polyembryony is defined as the splitting of one sexually produced embryo into many independent individuals. Approximately 20 years ago, Craig et al. (1997) reviewed the occurrence of polyembryony in animals. They included both fragmentation of embryonic stages and larval budding within the term polyembryony, whereas here we will limit our definition of polyembryony to asexual propagation prior to the formation of a definitive larva. Embryos and larvae commonly have different levels or degrees of tissue and structural organization, which allow for different mechanisms of asexual reproduction. For some terrestrial species (e.g., nine-banded armadillos and various species of parasitoid wasps), polyembryony is an obligate part of the life history where a single fertilized oocyte fragments to result in more than one developing embryo. Polyembryony has also been reported in a handful of species from the Bryozoa, Cnidaria, Echinodermata, and Platyhelminthes. Some species of cyclostome bryozoans (e.g., Crisia denticulata; Hughes et al., 2005) exhibit polyembryony via fragmentation of the cleaving embryo. Adults produce one or two primary embryos in the gonozooid that in turn divide to produce up to 100 secondary embryos (reviewed in Reed, 1991). These secondary embryos may also undergo facultative asexual propagation to yield many hundreds of embryos that complete development and that are released as lecithotrophic larvae. Polyembryony has been described for one species of cnidarian, the coral Acropora millepora, where environmental turbulence fragments early embryos and the isolated blastomeres can develop into complete larvae (Heyward and Negri, 2012). Among echinoderms, polyembryony has been observed in five species from the class Echinoidea: the sea urchins Prionocidaris baculosa (Mortensen, 1938), Eucidaris tribuloides, Lytechinus variegatus, and Strongylocentrotus droebachiensis, and the sand dollar Echinarachnius parma (Allen et al., 2015). The incidence of polyembryony in these species is highly variable and significantly impacted by changes in environmental conditions (e.g., salinity, discussed later). Finally, a species of ectoparasitic flatworm (phylum Platyhelminthes), Gyrodactylus elegans, also exhibits polyembryony but through a different mechanism involving unequal cleavage, instead of embryo fragmentation. For this species, a single fertilized egg undergoes unequal cleavage that produces a second embryo within the initial embryo, a third embryo within the second, and a fourth embryo within the third (Katheriner, 1904).

\subsubsection{Larva}

Asexual propagation at the larval stage has been reported in at least four phyla: Arthropoda, Cnidaria, Neodermata (within the traditional phylum Platyhelminthes), and Echinodermata (addressed in a separate section later). For those species where it has been described, asexual propagation occurs by budding, although the method of budding can be quite variable. Within the phylum Arthropoda, the parasitic rhizocephalan barnacles display a bizarre method of larval budding, where they use totipotent cells for host invasion (Glenner and Høeg, 1995). The cyprid larva settles on a decapod host and transforms into a kentrogon, which then injects a number of de-differentiated cells into the host. Each cell forms a vermiform stage that splits into individual cells that will form independent adults in different parts of the host. A similar "infective" single-cell stage may occur via amoeboid cells in narcomedusozoans (Russell, 1953), 
although the specific details are limited. For other species of narcomedusan hydrozoans (Osborn, 2000), scyphozoans (Berrill, 1949), one species of sea anemone (Edwardsiella lineata; Reitzel et al., 2009), and trematodes and cestodes (Katheriner, 1904; Poulin, 2007), a larva asexually propagates by budding from the existing larval tissue.

\subsection{Asexual Reproduction by Feeding Larvae of Echinoderms}

\subsubsection{Class-level Distribution of Larval Cloning in Echinoderms}

Asexual propagation by larvae has been most thoroughly described for planktotrophic larvae of echinoderms. A review by Mladenov (1996) summarized the occurrence of asexual reproduction in echinoderm classes and life history stages, where $1.3 \%$ of species undergo asexual reproduction as adults ( $0 \%$ of crinoids and echinoids, up to $2.2 \%$ of ophiuroids). Asexual reproduction by feeding larvae of echinoderms is known from four of five taxonomic classes (Asteroidea, Echinoidea, Holothuroidea, and Ophiuroidea), and is not known for larvae from the Crinoidea. Larval cloning is more broadly distributed among echinoderm classes than adult asexual reproduction despite the many fewer larval forms that have been studied, some exclusively from field samples.

Of all reports, evidence of cloning by larvae in the field is known only for some members of the Asteroidea and Ophiuroidea (Bosch et al., 1989; Bosch, 1992; Rao et al., 1993; Jaeckle, 1994; Balser, 1998; Knott et al., 2003; Galac et al., 2016). In the subtropical-tropical western Atlantic Ocean, asteroid larvae showing evidence of current and past asexual reproduction by paratomy are seasonally abundant (Jaeckle, 1994; Knott et al., 2003). Rao et al. (1993) also reported cloning larvae from the Bay of Bengal (northeast Indian Ocean), and there is an image of a cloning bipinnaria larva collected from waters surrounding the Great Barrier Reef (Image Quest Marine, personal communication). Two other forms of asexual reproduction are exhibited by fieldcollected asteroid larvae from the tropical western Atlantic Ocean: the release of the tips of larval arms (budding) by newly collected larvae has been infrequently observed and there is one larval form (tentatively assigned to the taxonomic order Paxillosida, family Astropectinidae) that asexually reproduces by autotomy of the preoral lobe (Jaeckle, 1994).

Cloning by ophiuroid larvae was originally suggested by Mortensen (1921) and described by Balser (1998) involving similar morphological changes to those observed in asteroids, but the clone is formed after the separation of the larval body from the fully formed juvenile. The remnants of the "primary" larva migrate to the vertex of the posterolateral arms and reiterate gastrulation (by invagination) and form the digestive system of the secondary larva. Balser (1998) reported that from a single fertilized egg of Ophiopholis aculeata two juveniles could be formed and that the development of second clonal generation for one individual was initiated.

Among asteroids, a cloning sequence similar to that exhibited by ophioplutei is hypothetically possible. Cloning by larvae could occur after a larva and the fully formed juvenile separate as the larval remnant may reenter the water column (e.g., Luidia sarsi). Although the digestive system of the persisting larval body contains only short esophageal and intestinal segments, these individuals can survive for some period of time (Tattersall and Sheppard, 1934). However, in culture they appear to be incapable of feeding on particulate foods and "as far as Luidia sarsi is concerned, regeneration followed by a second metamorphosis most probably never occurs" (Wilson, 1978, p. 475).

\subsection{Modes of Asexual Reproduction in Echinoderms}

\subsubsection{Asexual Reproduction by Budding}

Larval budding has been reported for members of the echinoderm classes Asteroidea (Jaeckle, 1994; Vickery and McClintock, 2000), Holothuroidea (Eaves and Palmer, 2003), and Echinoidea (Vaughn and Strathmann, 2008; Vaughn, 2009; 2010; McDonald and Vaughn, 2010). The details of this form of asexual reproduction among groups are not well described and the developmental sequence of events is, at best, superficially known. For asteroid larvae, the released apices of the larval arms appear to reiterate 
the sequence of development from a fertilized egg. Gastrulation by the blastula-stage secondary embryos reportedly occurs through unipolar invagination and the digestive system of the clone is derived from the ectoderm of the parent larva (Jaeckle, 1994). Although Jaeckle (1994) hypothesized that coelomogenesis in these embryos occurs through schizocoely, there are no new data that support this proposal.

\subsubsection{Asexual Reproduction by Paratomy}

Paratomous asexual reproduction by asteroid larvae (Figure 5.1) is known from individuals collected in plankton samples taken throughout the subtropicaltropical western Atlantic Ocean. To our knowledge, in all examined clones formed by paratomy of the posterolateral arms, the anterior-posterior axis of the developing clone is reversed to the anterior-posterior axis of the parent arm; the proximal (anterior) portion

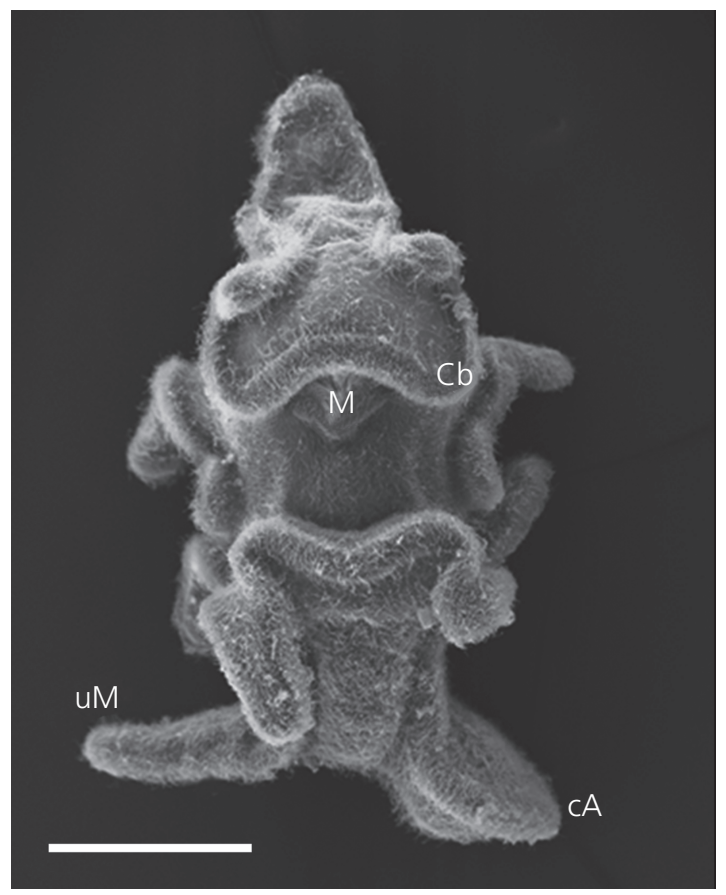

Figure 5.1 Scanning electron micrograph (ventral view) of a fieldcollected early brachiolaria larva showing an unmodified posterolateral arm ( $\mathrm{UM}$, left side) and a clonal arm ( $\mathrm{CA}$, right side) where the posterolateral arm is transforming into a new "secondary" larva through the process of paratomy. Symbols: $\mathrm{Cb}=$ ciliary band, $\mathrm{M}=$ mouth. Scale bar $=200 \mu \mathrm{m}$. of the parent arm corresponds to the posterior side of the offspring. How this axial inversion or any other attribute of asexual reproduction is genetically specified or regulated has not been identified.

Transformation of the posterolateral arms into new (secondary) individuals is morphologically signaled by the dissipation of the ciliary band that runs along the lateral sides of the posterolateral arm and the transformation of a simple epithelium into a stratified epithelium (Bosch et al., 1989). All known forms of cloning exhibited by asteroid larvae involve an apparent re-differentiation of cell fates. During the paratomous transformation, the presumptive ectoderm of the parent larva forms a new "secondary archenteron," which forms the digestive system of the clone.

The archenteron develops along the length of the transforming arm (Bosch et al., 1989; Figure 5.2).

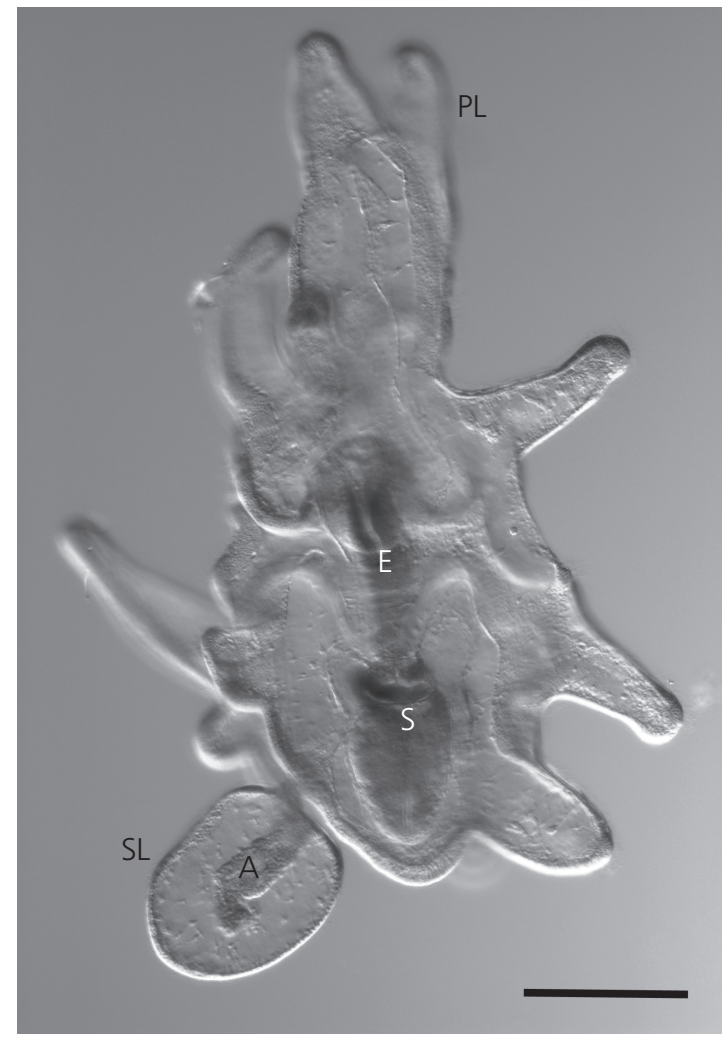

Figure $\mathbf{5 . 2}$ Light micrograph of a field-collected sea star larva with a gastrula-stage secondary larva (SL) forming from the posterolateral arm. Symbols: $\mathrm{A}=$ archenteron of clone, $\mathrm{E}=$ esophagus of the primary larva, $\mathrm{PL}=$ primary larva, $\mathrm{S}=$ stomach of the primary larva. Scale bar $=200 \mu \mathrm{m}$. 
However, it is unclear if the archenteron invaginates as a longitudinal furrow that closes along its length to leave a circular posterior opening or if it forms from a single invagination that extends distally within the blastocoel of the transforming arm. After the archenteron achieves its full length, the tubular gut differentiates to become the esophagus, stomach, and intestine, and the mouth is established as a new opening on the distal side of the transforming arm.

Coelom formation during the development of the secondary (clonal) larva remains incompletely described, but examination of physical and optical sections of cloning larvae indicates that secondary coelomogenesis occurs by enterocoely (Figure 5.3). Ultimately, a single presumptive coelom may lie lateral to the developing archenteron and extend beyond the archenteron in the distal side of the transforming larval arm.

Clonally produced individuals may separate from the parent as an early stage or fully formed

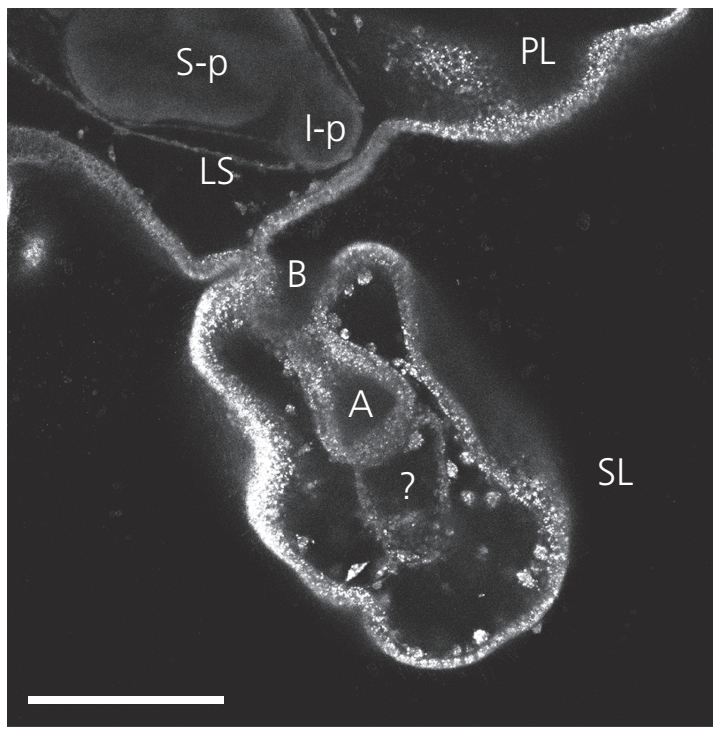

Figure 5.3 Combined optical sections $(\mathrm{N}=3)$ of a ventral view of a primary larva (PL) with an attached secondary larva (SL) forming through the process of paratomy. The secondary archenteron $(A)$ is continuous with a blastopore (B) and a thin-walled cavity whose developmental fate is unresolved. Symbols: I-p = intestine of primary larva, $L S=$ left somatocoel of the primary larva, $S-p=$ stomach of primary larva. The specimen was stained with Nile Red and examined using a Leica model TCS SP2 scanning laser confocal microscope. Scale bar $=150 \mu \mathrm{m}$. bipinnaria larva (Figure 5.4). Fully formed secondary bipinnariae may ingest particles prior to separation from the parent larva. The only known observation of the separation of the clone from the parent larva (of Luidia senegalensis) occurred as the clone rotated about the long axis of the transforming arm of the parent arm. This rotation tightened the stricture between the parent and clone and resulted in a breakage of the epithelial connection.

\subsubsection{Asexual Reproduction by Autotomy}

Mortensen (1898) illustrated a larva ("Auricularia paradoxa") collected from the tropical western Atlantic Ocean $\left(0^{\circ} 24^{\prime} \mathrm{N} ; 46^{\circ} 40^{\prime} \mathrm{W}\right)$ that resembles an asteroid larva with long posterolateral arms minus the preoral lobe. He described this larva by writing, "The opening of the mouth seems to lie very close to the anterior end, but everything which should be above the anterior transverse margin is wanting." Whether this individual was an auricularia larva (Holothuroidea) that was damaged during

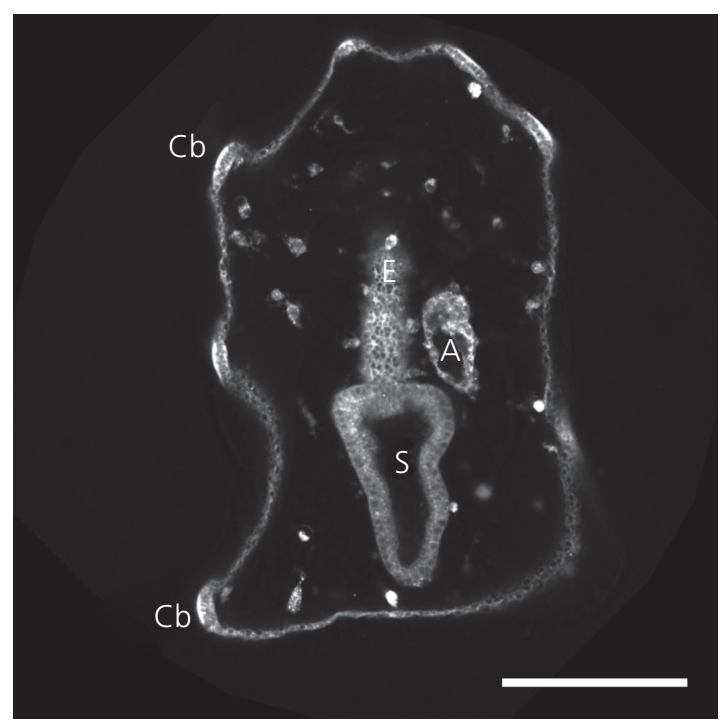

Figure 5.4 Combined optical sections $(\mathrm{N}=3)$ of a dorsal view of an independent secondary larva formed by the process of paratomy. The left axohydrocoel (A) extends a pore canal that fuses with the outer epithelium (not shown), but there is no evidence of a right axohydrocoel. Symbols: $\mathrm{Cb}=$ ciliary band, $\mathrm{E}=$ esophagus, $\mathrm{S}=$ stomach. The specimen was stained with Nile Red and examined using a Leica model TCS SP2 scanning laser confocal microscope. Scale bar $=100 \mu \mathrm{m}$. 
collection or an asteroid larva that had previously autotomized its preoral lobe is not known. Nearly 100 years later, Jaeckle (1994) described larvae collected from the subtropical western Atlantic Ocean with a common phenotype-but different from the larva described by Mortensen-that reproduced by autotomy of the preoral lobe. Autotomization of the preoral lobe was then reported for cultured larvae of several forcipulatid asteroids: Pisaster ochraceus (Vickery and McClintock, 2000), Distolasterias nipon (Kitazawa and Komatsu 2001), and Asterias forbesi (Blackburn and Allen, 2013, Figure 5.5). Autotomy by cultured pluteus larvae of the sand dollar Dendraster excentricus (order Clypeasteroida) was seen after larvae were exposed to fish mucus (Vaughn and Strathmann, 2008; Vaughn 2009; 2010) or acute increases in food abundance (MacDonald and Vaughn, 2010). Despite multiple observations of this form of cloning, the mechanism of asexual reproduction by autotomy is not known.

Examination of the "new" bipinnaria larvae formed by autotomy of the preoral lobe of the parent larva reveals apparent differences in the coelomic cavities. Examination of these small bipinnariae revealed a precocious development of the coelomic system, compared to a larva of similar size formed from a fertilized egg. In one individual at the time of collection, there was no evidence of a pore canal extending from the left axocoelic coelom or a dorsal pore ("hydropore").

\subsection{Induction of Asexual Reproduction}

Little is known about the factors that induce asexual reproduction in nature, but induction of polyembryony and larval cloning have been achieved using a number of different cues in laboratory settings. Understanding the forces responsible for inducing asexual reproduction, especially if they are rather common, may help us understand the frequency with which it occurs in nature. Studies to date suggest both abiotic and biotic factors can result in larval cloning in different species.

\subsubsection{Abiotic}

Abiotic cues of asexual reproduction include changes in environmental parameters, including $\mathrm{pH}$, salinity, temperature, and even the turbulence of the water. Few studies have investigated the degree to which these parameters (many of which are projected to covary in models of future climate change) may interact with one another to induce asexual reproduction. Independently, each condition has been demonstrated to play at least some role in inducing asexual reproduction and thus all are of great interest to both larval biologists and marine ecologists concerned about how recruitment patterns vary in space and time.

There is recent interest in how ocean acidification will affect the small, often partially calcified

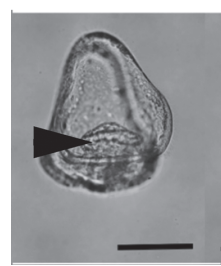

Day 7

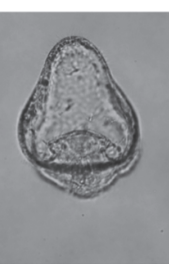

Day 8

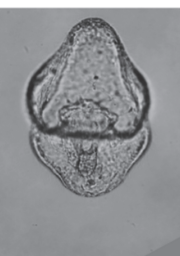

Day 9

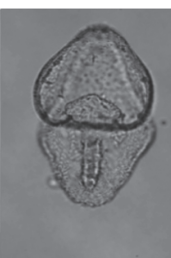

Day 10

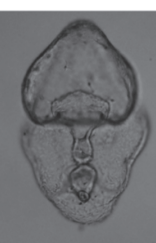

Day 11

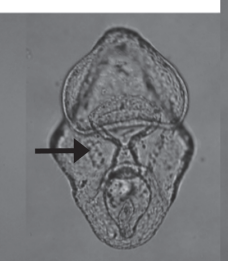

Day 12

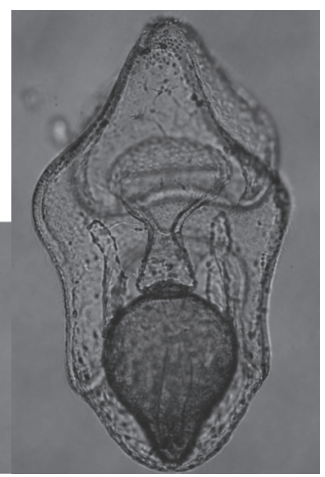

Day 19

Figure 5.5 Development/regeneration of the anterior portion of a bisected larva over 12 days. The preoral lobe was first observed floating in culture on Day 7. Arrowhead indicates larval mouth. Arrow indicates the reappearance of coelomic cavities. The dark coloration of the stomach on Day 19 indicates the presence of algal food following resumption of larval feeding. All images are at the same scale. Scale bar $=100 \mu \mathrm{m}$. All photos courtesy of Holly Blackburn. 
developing stages of marine invertebrates (reviewed by Byrne, 2011), but relatively little is known about the effect that acidification might have on the propensity of embryos or larvae to clone. Chan et al. (2013) demonstrated that $p \mathrm{CO}_{2}$ levels predicted for 2100 and 2300 induced high frequencies $(>50 \%)$ of budding for early larval stages of the purple sea urchin Strongylocentrotus purpuratus. However, none of the resultant buds survived for more than two days, calling into question the viability of asexually produced propagules and also raising the possibility that methods for rearing buds may differ from those sufficient to culture primary embryos and larvae. Low $\mathrm{pH}$ has also been reported to increase the frequency of conjoined twins in larvae of the gastropod Crepidula fornicata (Eyster, 1995), but there is as yet little evidence that this occurs in nature or that unjoined twins are ever produced.

Temperature has also been shown to affect the frequency of larval cloning in echinoderm larvae. In asteroids, Vickery and McClintock (2000) reported that temperature exerted a strong effect on the likelihood of larval cloning in the bipinnariae of the sea star Pisaster ochraceus. At low temperatures $\left(7-10^{\circ} \mathrm{C}\right)$ no larval cloning was observed, but at moderately increased temperatures $\left(12-15{ }^{\circ} \mathrm{C}\right)$ cloning was observed in about $6 \%$ of larvae in culture. At more extreme levels of temperature $\left(17-20{ }^{\circ} \mathrm{C}\right)$ no cloning was observed, but this result may have been confounded with high levels of mortality among primary larvae (Vickery and McClintock, 2000).

Similarly, few studies have assessed the role of salinity as a factor that induces asexual reproduction by echinoderm embryos. In 2015, Allen et al. described the role of salinity as a cue inducing polyembryony in early embryos of two sea urchins, the cidaroid Eucidaris tribuloides and the echinoid Echinarachnius parma. Reduced salinity resulted in higher frequencies of polyembryony in both species, but also interacted significantly with increasing temperature to yield even higher frequencies of polyembryony. Similar results have been found in a third echinoid species, the sand dollar Dendraster excentricus (Abdel Raheem and Allen, unpublished data). The interaction between salinity and temperature suggests that multiple factors may act in synergistic ways to influence frequencies of asexual reproduction (see later). Prior to this work,
Mortensen (1938) suggested that polyembryony may occur as part of the normal developmental pathway in another cidaroid, Prionocidaris baculosa, but provided no information on the environmental conditions (temperature, salinity, etc.) at which embryos were raised. Interestingly, embryos of two species of regular urchins (Strongylocentrotus droebachiensis and Lytechinus variegatus) have also been tested for similar responses to salinity, but very rarely exhibited polyembryony.

Environmental induction of polyembryony in irregular echinoids but not in regular echinoids is consistent with chemical induction of polyembryony as reported in a series of papers by Mazia and Vacquier (Mazia, 1958; Vacquier and Mazia, 1968a; b). Vacquier and Mazia (1968b) showed that the close association of blastomeres with the hyaline layer in regular echinoids kept cells pressed together even when cell-cell adhesion was disrupted by application of dithiothreitol (DTT). In contrast, application of DTT to Dendraster excentricus embryos with a looser association with the hyaline layer resulted in dissociation of cells from one another and ultimately polyembryony. Since the presence of $\mathrm{Ca}^{2+}$ ions is also required for normal interactions between blastomeres (Vacquier and Mazia, 1968a; b), it has been proposed that environmental induction of polyembryony at low salinities may result from lower concentrations of $\mathrm{Ca}^{2+}$ in low-salinity seawater (Allen et al., 2015), but this has yet to be formally tested. Regardless, the diversity of responses of regular and irregular echinoids to similar environmental conditions suggests these lineages may be promising models for future comparative studies of the mechanisms of asexual propagation of embryos.

The combination of multiple stressors, either taken from the previous list or unique ones not yet considered, may be a fruitful area for future research on the induction of asexual reproduction in embryos and larvae.

\subsubsection{Biotic}

In addition to the abiotic stimuli described earlier, there is increasing evidence that asexual reproduction may also be induced by interactions between larvae and other organisms in their environment. Biotic stimuli suggested to induce asexual 
reproduction include the amount of phytoplankton in culture (Vickery and McClintock, 2000; Eaves and Palmer, 2003), a sudden change in food abundance (McDonald and Vaughn, 2010), and the presence of chemical cues from a possible predator (Vaughn and Strathmann, 2008; Vaughn, 2009; 2010). The ability of larval stages to perceive and respond to biologically produced chemical cues in their environment is well known, and can be manifested in a number of ways, including plasticity in arm length in response to phytoplankton food (e.g., Hart and Strathmann, 1994; Miner, 2005), plasticity in shell morphology in response to predators (Vaughn, 2007), delays in hatching time in response to predators (Miner et al., 2010), and plasticity in settlement time in response to prey (Hadfield, 1977). Thus, it may not be surprising that to the degree planktonic larvae are able to reproduce asexually, they do so in response to biological cues in their environment. However, the frequency of biologically induced cloning events in nature is unknown. Only in a handful of controlled laboratory studies do we have any evidence for biological induction of asexual reproduction.

The most detailed examples of biotic stimuli inducing asexual reproduction come from studies of the effects of larval food supply (i.e., phytoplankton abundance) on clone production in echinoderms. In the ochre sea star, Pisaster ochraceus, Vickery and McClintock (2000) showed that cloning rates were highest when phytoplankton food was most abundant in culture and that a mixed diet (multiple species of phytoplankton) yielded higher rates of cloning than did a single-species diet. Similarly, phytoplankton abundance is also a cue for cloning in the pluteus larvae of the sand dollar, Dendraster excentricus (McDonald and Vaughn, 2010). In the case of $D$. excentricus, however, it is not the level of phytoplankton abundance that induces cloning, but rather a sudden shift in phytoplankton abundance (from low to high) that correlates with high frequencies (50-100\% of larvae) of clone production (McDonald and Vaughn, 2010).

Perhaps the most surprising example of biological stimuli inducing clone production also comes from $D$. excentricus, where pluteus larvae can be induced to produce clones via budding after exposure to mucus cues from planktivorous fish (Vaughn and Strathmann, 2008). The production of clones in response to fish mucus is highly variable and appears to be influenced by genetic (maternal) background (Vaughn, 2009). The reduced size of larval clones relative to primary larvae has been suggested to be an adaptive response (Vaughn and Strathmann, 2008; see further discussion later) to visual predators that are known to be size-specific in their feeding on larval echinoids, preferring larger larvae to smaller ones (Allen, 2008; Vaughn, 2010). However, as with phytoplankton cues, the prevalence of predator-induced cloning in nature is unknown and the mucus inducer of larval cloning is isolated from a benthic fish (the dover sole, Microstomus pacificus) that feeds preferentially on benthic polychaetes and ophiuroids as an adult (Gabriel and Pearcy, 1981), although the lengthy pelagic period of its larvae may provide an opportunity for planktivory on echinoids (Pearcy et al., 1977), though that has yet to be demonstrated.

\subsection{Other Taxa}

To date, only one study has examined the role of environmental turbulence in asexual reproduction, occurring in the scleractinian coral Acropora millepora (Heyward and Negri, 2012). Cloned coral embryos resulting from turbulence-induced blastomere separations at the two-, four-, and eight-cell stages were able to successfully complete development in the lab, albeit at smaller sizes. For embryos of $A$. millepora the levels of turbulence sufficient to induce cloning in the laboratory are equivalent to or less than those found in nature during the majority $(52 \%)$ of spawning events on the Great Barrier Reef. It is therefore likely that natural turbulence generates cloned coral embryos, although the fate of these embryos and the potential adaptive value of this response remains unknown.

\subsection{Is Larval Cloning Adaptive?}

As noted earlier, it is tempting to view asexual reproduction by embryos and larvae through the lens of adaptation, but the adaptive value of poorly understood phenotypes is difficult to demonstrate. The hypothesized benefits of asexual reproduction by embryos and larvae are intuitive, related 
to increasing the number of genotype copies. They could contribute to reproductive success in one or more ways. Cloning:

1. increases female fecundity without an apparent increase in resource allocation to reproduction;

2. may increase in the likelihood that a member of a genet survives;

3. may increase the probability that a member of a genet will locate a suitable settlement site by sampling a greater geographic area;

4. may reduce the genet's susceptibility to loss (i.e., predation) by increasing propagule number; and

5. may reduce the genet's susceptibility to loss (i.e., predation) by decreasing propagule size (Vaughn, 2010).

Nevertheless, the formation of each new individual (the clone) is a result of the loss of cell(s) from the "parent" embryo or larva, and this reduction in biomass may negatively influence the larva, the resulting juvenile, or both. The impact of this tissue loss on the survivorship of the parent is unknown, but it seems reasonable to hypothesize that the cost of asexual reproduction to the parent embryo or larva could include:

1. a decrease in larval feeding rate;

2. a decrease in larval grow rate;

3. an increase in the time to metamorphosis (with potentially increased exposure to planktonic predators); and

4. a decrease in juvenile size.

The extent to which any fitness trade-off varies among different forms of asexual reproduction by larvae is unknown. However, it seems reasonable to assume that any cost is correlated with two factors: (1) when asexual reproduction occurs during a species' life history and (2) the proportion of the primary individual's body that is allocated to cloning. Cloning by budding removes the smallest volume of material from the parent larva, and we hypothesize that this form of asexual reproduction has the smallest cost to the parent larva. Autotomy of the preoral lobe or paratomy of the posterolateral $\operatorname{arm}(\mathrm{s})$, in contrast, involves loss of a greater volume of tissue and potentially results in a greater cost to the parent larva through a reduction of feeding capacity, loss of biomass, or both. Yet the elements of both lists of "consequences" are plausible, but remain largely untested. The net effect of cloning is realized as the sum of these positive and negative consequences, and there is no a priori reason to expect that the result of this summation is constant from year to year.

To our knowledge, there is only one formal attempt to model the consequences of larval cloning. Rogers-Bennett and Rogers (2008) evaluated the influence of an unspecified form of larval cloning on dispersal distance. Their simulations predicted (1) that cloning increases the dispersal potential of a cohort of larvae, and (2) that the age of parent larvae when asexually produced offspring are released was positively related to the dispersal potential of the cohort. Their model, however, did not incorporate any estimates of the cost(s) of asexual reproduction to the parent larva or to the subsequent juvenile.

Although the costs and benefits that may select for evolution of larval cloning in marine invertebrates remain understudied in free-living marine species, asexual reproduction of developmental stages in parasitic species are better characterized. Endoparasitic larval stages of digeneans, cestodes, and other parasitic Platyhelminthes (Neodermata) commonly exhibit asexual propagation in intermediate hosts. For example, the miracidium stage that infects a snail host can asexually replicate itself to generate thousands of cercariae, the next stage in the life history. The extent of asexual reproduction in these larval stages can vary widely due to taxonomic group (Rohde, 1982, p. 54) and a number of interrelated life history factors summarized by Poulin (2007), including host size and infection longevity (Keeney et al., 2008), competition (Hendrickson and Curtis, 2002), and adult size or longevity (Moore, 1981).

In schistosome species, the extent of asexual reproduction in the miracidium stage is an apparent trade-off with oocyte production, where larger embryos have higher asexual reproduction rates (Loker, 1983). The increased number of asexually produced individuals may represent one adaptive mechanism for increasing successful transmission to a second intermediate or terminal host, a step in the life history which may occur at a low frequency due to death of the current host or low encounter 
rates with the next host. Asexual reproduction of endoparasitic larvae in hosts may also be a common strategy in other parasitic species, including the sea anemone Edwardsiella lineata, where larval cloning occurs and parasite number correlates with host size (Reitzel et al., 2009). We can hypothesize that larvae of nonparasitic species may be selected for asexual reproduction due to similar trade-offs in the plankton, where different selection pressures (e.g., likelihood of predation, feeding environment, probability of successful settlement) may result in positive selection for asexual reproduction in a species-dependent manner. Discerning between potential selective factors will require a combination of laboratory experimentation and resolved phylogenetic relationships for closely related species with and without larval asexual propagation.

\subsection{Open Questions for Future Research}

(1) Does asexual reproduction by cultured larvae offer a window to natural phenomena or represent an induced developmental response to unnatural environmental conditions?

Production of asexual propagules in response to environmental conditions or changes in conditions (food abundance: Vickery and McClintock, 2000; Eaves and Palmer, 2003; McDonald and Vaughn, 2010; possible predators: Vaughn and Strathmann, 2008; Vaughn, 2009; 2010) are known from in vitro experiments. Consequently, it is not certain whether examples of asexual reproduction by embryos or larvae in culture represent natural phenomena or are developmental events induced by culture conditions. There is evidence provided by early workers (e.g., Gemmill, 1914; 1915; MacBride, 1918) that deviations from normal development (e.g., larvae with multiple or no pore canals) could be induced by culture conditions.

Echinoderm embryos and larvae exhibit a tremendous capacity for regeneration. Research has demonstrated that bisected echinoderm larvae of sea stars (Pisaster ochraceus, Luidia foliolata, and Patiria miniata) and sea urchins (Dendraster excentricus and Lytechinus variegatus) are capable of regrowing the excised portions of their body (Vickery and McClintock, 1998; Vickery et al., 2002; Oulhen et al., 2016). In most cases, the regenerated larvae successfully completed metamorphosis to produce a benthic juvenile. A more extreme example of the regenerative potential of developmental stages of echinoderms was described by Dan-Sohkawa et al. (1986). They dissociated gastrula-stage embryos of the sea star Asterina pectinifera using osmotic, ionic, and physical forces, and then followed the re-aggregation of the isolated cells (or groups of cells). From the initial suspension of cells, a free-swimming, blastula-like embryo was established after $\approx 30 \mathrm{~h}$ post-dissociation. After $80-100$ h post-dissociation, bipinnaria-stage larvae were reconstructed. Tamura et al. (1998) examined the morphological events of secondary coelomogenesis and described two different processes that created the "coelomic pouches." In some larvae (37 of 62 individuals) a coelomic pouch was established through processes reminiscent of enterocoelly ("enterocoel-like" coelom formation), while in other individuals (22 of 62 individuals) coeloms were established by an aggregation of mesenchyme-like cells ("schizocoeliclike" coelom formation); three reconstructed larvae formed coeloms through both processes. Not all reconstructed larvae were developmentally normal as some individuals developed a multiple or a branched digestive system.

(2) Does asexual reproduction occur in all groups of echinoderms, but the frequency of occurrence in some groups is too low to detect in samples from the field?

Among echinoderm species that produce developmental stages that undergo asexual reproduction, only cloning larvae of some species of the Asteroidea and the Ophiuroidea have been identified from plankton samples. However, species of the Echinoidea and Holothuroidea are known to reproduce asexually in laboratory cultures. If asexual reproduction occurs in all groups, but at a variable and, in some cases, low frequency, then detection of cloning by embryos or larvae in laboratory cultures where large numbers of individuals can be evaluated is not surprising. A low frequency of occurrence coupled with rapid rates of clone formation (e.g., Vaughn, 2009) further reduces the likelihood of detecting rare, fast-developmental events from field samples. MacBride (1918) similarly commented on the frequency of developmental abnormalities in coelomogenesis of echinoderm larvae: "In this list of recorded instances of the occurrence 
of two hydrocoels among echinoderm larvae, it will be noticed that only one such specimen was found among larvae fished from the open sea, although hundreds of such larvae have been examined." We are hopeful that further field sampling will reveal the presence of cloning larvae of echinoids and holothuroids.

(3) How does the ability of larvae to clone evolve in marine invertebrate lineages?

Currently, most descriptions of larval cloning have been scattered throughout lineages, potentially due to opportunistic observations or studies in species that can be cultured in the laboratory. If asexual reproduction is a component of a life history that is under selection, we would expect it to be gained and lost in lineages in the same way as any other character. Research in gains and/or losses of asexual reproduction in sea anemones (Geller and Walton, 2001) as well as regeneration in annelids (Bely and Sikes, 2010) and other spiralians (Bely et al., 2014) suggest that these developmental processes can be quite dynamic within particular lineages. The evolution of mechanisms of asexual reproduction requires explicit comparison in a resolved phylogeny where the presence or absence of "asexual reproduction" by embryos or larvae can be mapped to determine if this is a primitive or a derived life history character.

In asteroids, current evidence hints that larval asexual reproduction may have evolved multiple times. Cloning larvae have been collected from opportunistic sampling from Barbados, Panama, Belize, Jamaica, Commonwealth of the Bahamas, Gulf of Mexico, and throughout the Gulf Stream system. Despite this regional geographic distribution and high seasonal abundances (Knott et al., 2003), the species identity of cloning asteroid larvae remains poorly resolved. Using morphological features of collected larvae, Bosch et al. (1989) assigned cloning bipinnariae from the Sargasso Sea to the genus Luidia (order Paxillosida). Further samples from the waters surrounding the Commonwealth of the Bahamas and from the Florida Current of the Gulf system revealed the presence of cloning larvae from a non-paxillosid group (Jaeckle, 1994). Knott et al. (2003) compared tRNA gene sequences and recognized three groups of cloning asteroid larvae (that nested among species of the taxonomic families
Luidiidae, order Paxillosida, Ophidiasteridae, order Valvatida, and Oreasteridae, order Valvatida), but genus and species-level identities could not be resolved. More recently, Galac et al. (2016) sequenced mitochondrial and nuclear genes from cloning and aclonal bipinnariae and brachiolariae collected from the Florida Current of the Gulf Stream system expressing the same color phenotype. Through their analysis they assigned these specimens to a single, yet undescribed, species within the family Oreasteridae. Their species was equivalent to "Larval Group 1" reported by Knott et al. (2003). To our knowledge the only species of asteroid echinoderm known to produce secondary larvae by paratomy is Luidia senegalensis (W. Jaeckle, personal observation). This specimen was identified based on the number of arm rays of the juvenile.

(4) Will changing climate lead to increased asexual reproduction by larvae?

There is abundant evidence that climate change will result in changes in ocean conditions that are likely to have strong effects on microscopic larvae. Given what is known about abiotic induction of polyembryony and larval cloning (see earlier), there is reason to believe that some potential outcomes of climate change will also lead to increased frequency of asexual reproduction. First, phytoplankton blooms may shift in their frequency, intensity, and location under future climate change scenarios. It is likely these changes will be uneven and likely difficult to predict. For example, in the North Atlantic warming sea surface temperatures have resulted in both increased (in cooler regions) and decreased (in warmer regions) phytoplankton abundance (Richardson and Schoeman, 2004). If the overall levels of phytoplankton increase, or if the speed and intensity of bloom appearance increase, current research (Vickery and McClintock, 2000; McDonald and Vaughn, 2010) suggests that larval cloning may be facilitated.

Concurrent with ocean warming, there has also been a freshening of the surface waters where the development of marine invertebrates frequently occurs. While freshening is not uniform globally, major portions of the world's oceans are freshening, including the Gulf of Maine (notably on Georges Bank), parts of the Indian and Pacific Oceans and the Southern Ocean (Wong et al., 1999; Drinkwater et al., 2009; Haumann et al., 2016). Since at least 
some cases of polyembryony are reported to occur in response to elevated temperature and concomitant reductions in salinity (Allen et al., 2015), it may be of special interest for developmental biologists and larval ecologists to examine fieldcollected embryos and larvae for signs of polyembryony and cloning in areas where the interactive effects of temperature rise and salinity decline may be strongest. Greater understanding of the physiological tolerances and responses of embryos and larvae, along with improved understanding of the mechanisms of asexual reproduction are needed before any substantive predictions can be made in this regard.

\subsection{Summary}

1. Larvae in multiple phyla of marine invertebrates undergo asexual reproduction, with most observations occurring under laboratory conditions.

2. Echinoderms, particularly asteroids and echinoids, are the most thoroughly described group with respect to the diversity of modes of asexual reproduction as well as the occurrence of clonal reproduction in the natural environment.

3. Numerous abiotic and biotic factors have been described that result in increased frequency of asexual reproduction events in echinoderm larvae, suggesting that larvae may respond to diverse environmental signals by initiating a cloning response.

4. The fitness costs of cloning to the "parent" larva and how those costs may vary among different forms of asexual reproduction are unknown and warrant future study.

5. Future studies aimed at dissecting the evolutionary gains and losses of larval cloning in particular groups, as well as the frequency of cloning in natural environments will provide essential data to better understand how and why larvae of particular species have included asexual reproduction as part of their life history.

6. Future work on the developmental biology of asexual reproduction is needed to determine if the processes of asexual reproduction by freeliving larvae are different reiterations of development from zygotes or if they represent developmental novelties.

\section{Acknowledgment}

We acknowledge the assistance of Dr. Uwe Staerzfor who provided a translation of Mortensen's (1898) description of "Auricularia paradoxa."

AMR would like to thank the University of North Carolina at Charlotte for support through a Junior Faculty Development Award.

\section{References}

Allen, J.D. 2008. Size-specific predation on marine invertebrate larvae. Biological Bulletin 214: 42-49.

Allen, J.D., Armstrong, A.F., and Ziegler, S.L. 2015. Environmental induction of polyembryony in echinoid echinoderms. Biological Bulletin 229: 221-231.

Alvarado, A.S. 2000. Regeneration in the metazoans: why does it happen? BioEssays 22: 578-590.

Balser, E.J. 1998. Cloning by ophiuroid echinoderm larvae. Biological Bulletin 194: 187-193.

Bely, A.E. and Sikes, J.M. 2010. Latent regeneration abilities persist following recent evolutionary loss in asexual annelids. Proceedings of the National Academy of Sciences of the United States of America 107: 1464-1469.

Bely, A.E., Zattara, E.E., and Sikes, J.M. 2014. Regeneration in spiralians: evolutionary patterns and developmental processes. International Journal of Developmental Biology 58: 623-634.

Berrill, N.J. 1949. Developmental analysis of Scyphomedusae. Biological Reviews 24: 393-410.

Blackburn, H.N. and Allen, J.D. 2013. Maternal effects on cloning frequency, larval development and juvenile size in the sea star Asterias forbesi. Integrative and Comparative Biology 53: E18.

Blackstone, N.W. and Jasker, B.D. 2003. Phylogenetic considerations of clonality, coloniality, and, mode of germline development in animals. Journal of Experimental Zoology 297B: 35-47.

Bosch, I. 1992. Symbiosis between bacteria and oceanic clonal sea star larvae in the western North Atlantic Ocean. Marine Biology 114: 495-502.

Bosch, I., Rivkin, R.B., and Alexander, S.P. 1989. Asexual reproduction by oceanic planktotrophic echinoderm larvae. Nature 337: 169-170.

Byrne, M. 2011. Impact of ocean warming and ocean acidification on marine invertebrate life history stages: vulnerabilities and potential for persistence in a changing ocean. Oceanography and Marine Biology: An Annual Review. 49: 1-42.

Chan, K.Y.K., Grünbaum, D., Arnberg, M., Thorndyke, M. et al. 2013. Ocean acidification induces budding in larval sea urchins. Marine Biology 160: 2129-2135. 
Christiansen, F B. and Fenchel, T.M. 1979. Evolution of marine invertebrate reproductive patterns. Theoretical Population Biology 16: 267-282.

Craig, S.F., Slobodkin, L.B., Wray, G.A., and Biermann, C.H. 1997. The "paradox" of polyembryony: a review of the cases and a hypothesis for its evolution. Evolutionary Ecology 11: 127-143.

Dan-Sohkawa, M., Yamanaka, H. and Watanabe, K. 1986. Reconstruction of bipinnaria larvae from dissociated embryonic cells of the starfish, Asterina pectinifera. Journal of Embryology and Experimental Morphology 94: 47-60.

Drinkwater, K.F., Mueter, F., Friedland, K.D., Taylor, M. et al. 2009. Recent climate forcing and physical oceanographic changes in Northern Hemisphere regions: a review and comparison of four marine ecosystems. Progress in Oceanography 81: 10-28.

Eaves, A.A. and Palmer, A.R. 2003. ReproductionWidespread cloning in echinoderm larvae. Nature 425: 146.

Emlet, R.B. and Hoegh-Guldberg, O. 1997. Effects of egg size on postlarval performance: experimental evidence from a sea urchin. Evolution 51: 141-152.

Emlet, R.B., McEdward, L.R., and Strathmann, R.R. 1987. Echinoderm larval ecology viewed from the egg. Echinoderm Studies 2: 55-136.

Eyster, L.S. 1995. Conjoined twins, triplets, and quadruplets in the gastropod Crepidula fornicata. Invertebrate Biology 114: 307-323.

Ferretti, P. and Geraudie, J. 2001. Cellular and Molecular Basis for Regeneration: From Invertebrates to Humans. New York: Wiley and Sons.

Gabriel, W.L. and Pearcy, W.G. 1981. Feeding selectivity of Dover sole, Microstomus pacificus, off Oregon. Fishery Bulletin 79: 749-763.

Galac, M., Bosch, I., and Janies, D. 2016. Bacterial communities of oceanic sea star (Asteroidea: Echinodermata) larvae. Marine Biology 163: 162.

Geller, J.B. and Walton, E.D. 2001. Breaking up and getting together: evolution of symbiosis and cloning by fission in sea anemones (Genus Anthopleura). Evolution 55: $1781-1794$.

Gemmill, J.F. 1914. The development and certain points in the adult structure of the starfish Asterias rubens, L. Philosophical Transactions of the Royal Society B: Biological Sciences 205: 2 13-294.

Gemmill, J.F. 1915. Double hydrocoele in the development and metamorphosis of the larva of Asterias rubens, L. Journal of Cell Science 61: 51-80.

Gerber, N. and Kokko, H. 2016. Sexual conflict and the evolution of asexuality at low population densities. Proceedings of the Royal Society of London. Series B, Biological Sciences 283: 1280.
Glenner, H. and Høeg, J.T. 1995. A new motile, multicellular stage involved in host invasion by parasitic barnacles (Rhizocephala). Nature 377: 147-150.

Hadfield, M.G. 1977. Chemical interactions in larval settling of a marine gastropod. In: D.J. Faulkner and W.H. Fenical WH (eds.), Marine Natural Products Chemistry, pp. 403-412. New York: Plenum.

Hart, M.W., Byrne, M., and Smith, M.J. 1997. Molecular phylogenetic analysis of life-history evolution in asterinid starfish. Evolution 51: 1848-1861.

Hart, M.W. and Strathmann, R.R. 1994. Functional consequences of phenotypic plasticity in echinoid larvae. Biological Bulletin 186: 291-299.

Haumann, F.A., Gruber, N., Munnich, M., Frenger, I. et al. 2016. Sea-ice transport driving Southern Ocean salinity and its recent trends. Nature 537: 89-92.

Hendrickson, M.A. and Curtis, L.A. 2002. Infrapopulation sizes of co-occurring trematodes in the snail Ilyanassa obsoleta. Journal of Parasitology 88: 884-889.

Heyward, A.J. and Negri, A.P. 2012. Turbulence, cleavage, and the naked embryo: a case for coral clones. Science 335: 1064 .

Hughes, R.N., D'Amato, M.E., Bishop, J.D., Carvalho, G.R. et al. 2005. Paradoxical polyembryony? Embryonic cloning in an ancient order of marine bryozoans. Biology Letters 1: 178-180.

Hurst, L.D. and Peck, J.R. 1996. Recent advances in understanding of the evolution and maintenance of sex. Trends in Ecology and Evolution 11: A46-A52.

Jaeckle, W.B. 1994. Multiple modes of asexual reproduction by tropical and subtropical sea star larvae-an unusual adaptation for genet dispersal and survival. Biological Bulletin 186: 62-71.

Jeffery, W.R. and Swalla, B.J. 1992. Evolution of alternate modes of development in ascidians. BioEssays 14: 219-226.

Judson, O.P. and Normark, B.B. 1996. Ancient asexual scandals. Trends in Ecology and Evolution 11: A41-A46.

Katheriner, L. 1904. Über die Entwicklung von Gyrodactylus elegans von Nordmann., Zoologische Jahrbücher Festschrift Weissmann Suppl. 7: 519-550.

Keeney, D.B., Boessenkool, S., King, T.M., Leung, T.LF. et al. 2008. Effects of interspecific competition on asexual proliferation and clonal genetic diversity in larval trematode infections of snails. Parasitology 135: 741-747.

Kitazawa, C., and Komatsu, M. 2001. Larval development and asexual development of the sea star, Distolasterias nipon (Doderlein). In: M.F. Barker (ed.), Echinoderms 2000. Swets and Zeitlinger, Lisse, The Netherlands.

Knott, K.E., Balser, E.J., Jaeckle, W.B., and Wray, G.A. 2003. Identification of asteroid genera with species capable of larval cloning. Biological Bulletin 204: 246-255. 
Krug, P.J. 1998. Poecilogony in an estuarine opisthobranch: planktotrophy, lecithotrophy, and mixed clutches in a population of the ascoglossan Alderia modesta. Marine Biology 132: 483-494.

Levitan, D.R. 2000. Optimal egg size in marine invertebrates: theory and phylogenetic analysis of the critical relationship between egg size and development time in echinoids. American Naturalist 156: 175-192.

Loker, E.S. 1983. A comparative study of the life-histories of mammalian schistosomes. Parasitology 87: 343-369.

MacBride, E.W.1918.The artificial production of echinoderm larvae with two water-vascular systems, and also of larvae devoid of a water-vascular system. Proceedings of the Royal Society of London. Series B, Biological Sciences 90: 323-348.

Maynard Smith, J. 1971. What use is sex? Journal of Theoretical Biology 30: 319-335.

Mazia, D. 1958. SH compounds in mitosis. I. The action of mercaptoethanol on the eggs of the sand dollar Dendraster excentricus. Experimental Cell Research 14: 486-494.

McDonald, K.A. and Vaughn, D. 2010. Abrupt change in food environment induces cloning in plutei of Dendraster excentricus. Biological Bulletin 219: 38-49.

McEdward, L.R. and Janies, D.A. 1997. Relationships among development, ecology, and morphology in the evolution of Echinoderm larvae and life cycles. Biological Journal of the Linnean Society 60: 381-400.

McHugh, D. and Rouse, G.W. 1998. Life history evolution of marine invertebrates: new views from phylogenetic systematics. Trends in Ecology and Evolution 13: 182-186.

Miner, B.G. 2005. Evolution of feeding structure plasticity in marine invertebrate larvae: a possible trade-off between arm length and stomach size. Journal of Experimental Marine Biology and Ecology 315: 117-125.

Miner, B.G., Donovan, D.A., and Andrews, K.E. 2010. Should I stay or should I go: predator- and conspecific-induced hatching in a marine snail. Oecologia (Berlin) 163: 69-78.

Mladenov, P.V. 1996. Environmental factors influencing asexual reproductive processes in echinoderms. Oceanologica Acta 19: 227-235.

Moore, J. 1981. Asexual reproduction and environmental predictability in cestodes (Cyclophyllidae: Taeniidae). Evolution 35: 723-741.

Mortensen, T.H. 1898. Die Echinodermenlarven der Plankton-Expedition nebst einer systematischen Revision der bisher bekannten Echinodermenlarven. Ergebnisse der Plankton-Expedition der Humboldt-Stiftung 2J: 1-118.

Mortensen, T.H. 1921. Studies of the Development and Larval Forms of Echinoderms. Copenhagen: GEC Gad.

Mortensen, T. 1938. Contributions to the study of the development and larval forms of echinoderms. IV. Det Kongelige Danske Videnskabernes Selskabs Skrifter Naturvidenskabelig og Mathematisk Afdeling series 9, 7: 1-59.
Osborn, D.A. 2000. Cnidarian "parasites" on Solmissus incisa, a narcomedusa. Scientia Marina 64: 157-163.

Oulhen, N., Heyland, A., Carrier, T.J., Zazueta-Novoa, V. et al. 2016. Regeneration in bipinnaria larvae of the bat star Patiria miniata induces rapid and broad new gene expression. Mechanisms of Development 142: 10-21.

Pearcy, W.G., Hosie, M.J., and Richardson, S.L. 1977. Distribution and duration of pelagic life of larvae of Dover sole, Microstomus pacificus; Rex sole, Glyptocephalus zachirus; and Petrale sole, Eopsetta jordani, in waters off Oregon. Fishery Bulletin 75: 173-183.

Poulin, R. 2001. Progenesis and reduced virulence as an alternative transmission strategy in a parasitic trematode. Parasitology 123: 623-630.

Poulin, R. 2007. Evolutionary Ecology of Parasites (2nd ed.). Princeton University Press, Princeton, NJ.

Rao, P.S., Rao, K.H., and Shyamasundari, K. 1993. A rare condition of budding in bipinnaria larva (Asteroidea). Current Science 65: 792-793.

Reed, C.G. 1991. Bryozoa. In: A.G. Giese, J.A. Pearse, V.B. and Pearse (eds.), Reproduction of Marine Invertebrates. Volume 6: Echinoderms and Lophophorates, pp. 85-245. Boxwood Press, Pacific Grove, CA.

Reitzel, A.M., Daly, M., Sullivan, J.C., and Finnerty, J.R. 2009. Comparative anatomy and histology of developmental and parasitic stages in the life cycle of the lined sea anemone Edwardsiella lineata. Journal of Parasitology 95: 100-112.

Richardson, A.J. and Schoeman, D.S. 2004. Climate impact on plankton ecosystems in the Northeast Atlantic. Science 305: 1609-1612.

Rogers-Bennett, L. and Rogers, D.W. 2008. Modeling dispersal of cloning echinoderm larvae with a Gaussian distribution: forever young? California Cooperative Oceanic Fisheries Investigations Report 49: 232-240.

Rohde, K. 1982. Ecology of Marine Parasites. University of Queensland Press, St. Lucia.

Rouse, G. and Fitzhugh, K. 1994. Broadcasting fables-is external fertilization really primitive - sex, size, and larvae in sabellid polychaetes. Zoologica Scripta 23: 271-312.

Russell, F.S. 1953. The Medusae of the British Isles. Anthomedusae, Leptomedusae, Limnomedusae, Trachymedusae and Narcomedusae. Cambridge University Press, London.

Sinervo, B. and McEdward, L.R. 1988. Developmental consequences of an evolutionary change in egg size-an experimental test. Evolution 42: 885-899.

Strathmann, R.R. 1985. Feeding and nonfeeding larval development and life-history evolution in marine invertebrates. Annual Review of Ecology and Systematics 16: 339-361.

Tamura, M., Dan-Sohkawa, M. and Kaneko, H. 1998. Coelomic pouch formation in reconstructing embryos of the starfish Asterina pectinifera. Development, Growth $\mathcal{E}$ Differentiation 40: 567-575. 
Tattersall, W.M. and Sheppard, E.M. 1934. Observations on the bipinnaria of the asteroid genus Luidia. In: R.J. Daniel (ed.) James Johnstone Memorial Volume, pp. 35-61. University Press of Liverpool, Liverpool, UK.

Vacquier, V.D. and Mazia, D. 1968a. Twinning of sand dollar embryos by means of dithiothreitol. The structural basis of blastomere interactions. Experimental Cell Research 52: 209-221.

Vacquier, V.D. and Mazia, D. 1968b. Twinning of sea urchin embryos by treatment with dithiothreitol. Roles of cell surface interactions and of the hyaline layer. Experimental Cell Research 52: 459-468.

Vance, R.R. 1973. On reproductive strategies in marine benthic invertebrates. American Naturalist 107: 339-352.

Vaughn, D. 2007. Predator-induced morphological defenses in marine zooplankton: a larval case study. Ecology 88: $1030-1039$.

Vaughn, D. 2009. Predator-induced larval cloning in the sand dollar Dendraster excentricus: might mothers matter? Biological Bulletin 217: 103-114.

Vaughn, D. 2010. Why run and hide when you can divide? Evidence for larval cloning and reduced larval size as an adaptive inducible defense. Marine Biology 157: 1301-1312.
Vaughn, D. and Strathmann, R.R. 2008. Predators induce cloning in echinoderm larvae. Science 319: 1503.

Vickery, M.S. and McClintock, J.B. 1998. Regeneration in metazoan larvae. Nature 394: 140.

Vickery, M.S. and McClintock, J.B. 2000. Effects of food concentration and availability on the incidence of cloning in planktotrophic larvae of the sea star Pisaster ochraceus. Biological Bulletin 199: 298-304.

Vickery, M.S., Vickery, M.C.L., and McClintock, J.B. 2002. Morphogenesis and organogenesis in the regenerating planktotrophic larvae of asteroids and echinoids. Biological Bulletin 203: 121-133.

Wilson, D.P. 1978. Some observations on bipinnariae and juveniles of the starfish genus Luidia. Journal of the Marine Biological Association of the United Kingdom 58: 467-478.

Wong, A.P.S., Bindoff, N.L., and Church, J.A. 1999. Largescale freshening of intermediate waters in the Pacific and Indian Oceans. Nature 400: 440-443.

Wray, G.A. 1995. Evolution of larvae and developmental modes. In: L.R. McEdward (ed.), Ecology of Marine Invertebrate Larvae, pp. 413-447. CRC Press, Boca Raton, FL. 